\title{
KÖMÜR FLOTASYONUNDA FARKLI YAĞLARIN PERFORMANSLARININ KARŞILAŞTIRILMASI
}

\author{
Ercan ŞAHINOĞLU \\ Karadeniz Teknik Üniversitesi, Mühendislik Fakültesi, Maden Mühendisliği Bölümü, TRABZON \\ ercansahinoglu@ktu.edu.tr
}

(Geliş/Received: 13.11.2018; Kabul/Accepted in Revised Form: 26.12.2018)

ÖZ: Kömür tanelerinin hidrofobisitesini arttırmak için mazot, gazyağı ve fuel oil gibi yağlar kömür flotasyonunda toplayıcı olarak endüstriyel ölçekte kullanılmaktadır. Bu çalışmada, dört farklı tipte yağın (mazot, fuel oil, orijinal ayçiçek yağı, atık ayçiçek yağı) yüksek kül $(\% 35,65)$ ve kükürt $(\% 7,91)$ içerikli toz boyutlu $(-0,25 \mathrm{~mm})$ kömürde flotasyon performansı araştırılmıştır. En yüksek yanabilir verim toplayıcı olarak mazot kullanılması durumunda \%87,48 olarak elde edilmiştir. En fazla kül giderimi ise \%58,36 olarak fuel oil kullanıldığında gerçekleşmiştir. Kömürün flotasyon ile zenginleştirilmesinde, petrol kökenli yağlara alternatif olarak kolay bulunabilen, yenilenebilir bitkisel kökenli yağında kullanılabileceği belirlenmiştir. Ayrıca atık ayçiçek yağının performansının (yanabilir verim \%84,19 ve kül giderimi \%56,17) diğer yağların performansına yakın olduğu sonucuna ulaşılmıştır.

Anahtar Kelimeler: Kömür flotasyonu, Bitkisel yă̆, Yanabilir verim, Kül giderimi, Ayırma etkinliği

\section{Comparison of Performance of Different Oils in Coal Flotation}

ABSTRACT: Oils such as diesel oil, kerosene and fuel oil are used as collectors in coal flotation in order to increase the hydrophobicity of the coal particles. In the current study, the effect of four different type of oils (diesel oil, fuel oil, original sunflower oil, waste sunflower oil) were investigated on flotation performance of a coal in powder form $(-0.25 \mathrm{~mm})$ with high ash $(35.65 \%)$ and sulphur $(7.91 \%)$ content. Maximum combustible recovery with $87.48 \%$ was achieved using diesel oil as the collector. Maximum ash rejection by $58.36 \%$ was obtained using fuel oil. It has been determined that it can be used as an alternative to petroleum based oils and can be used as a renewable vegetable based oil in the enrichment of coal with flotation. Furthermore, it was concluded that the performance of waste sunflower oil (combustible recovery of $84.19 \%$, ash rejection of $56.17 \%$ ) is close to the performance of other oils.

Key Words: Coal flotation, Vegetable oil, Combustible recovery, Ash rejection, Separation efficiency

\section{GİRIŞ (INTRODUCTION)}

Kömür, dünya enerji ihtiyacının karşılanmasında önemli bir rol üstlenmiş olan katı fosil bir yakıttır (Xia ve diğ., 2018). Dünya genelinde bir değerlendirme yapıldığında petrol rezervlerinin 40, doğalgaz rezervlerinin 60, kömür rezervlerinin de 200 yıllık bir ömre sahip olduğu tahmin edilmektedir (Alp ve diğ., 2017). Kömürün önümüzdeki onlarca yıl lider enerji kaynağı olmayı sürdürecek olması ve gelişen teknolojiye paralel olarak üretiminde artan toz boyutlu kömür oranı, toz boyutlu kömürlerin temizlenmesine olan ilginin artmasına neden olmuştur (Gülsuna ve Bayat, 2010).

Türkiye, kömür rezervleri açısından oldukça zengin olmasına karşın bu rezervlerin çoğunluğunun yüksek kül, kükürt ve nem içeriğinden dolayı düşük kaliteli olduğu görülmektedir. Ülkemizde yüksek 
kül/kükürt içeriğine sahip olduğu halde temizlenmeden kullanıldığı için değer kaybına uğrayan ve çevresel kirliliğe yol açan kömürlerin temizlenerek çevre dostu enerji yakıtı haline getirilmeleri ve ekonomik değerlerinin artırılması ülkemiz açısından oldukça önemlidir (Şahinoğlu, 2012).

Toz boyutlu kömürlerin temizlenmesinde kullanılan çeşitli yöntemler vardır. Bu yöntemler flotasyon, yağ aglomerasyonu, seçici flokülasyon ve geliştirilmiş gravite ayırıcıları (kelsey jig, multi gravite ayırıcısı, falcon konsantratörü ve knelson konsantratör) dir (Kawatra ve Eisele, 2001; Şahinoğlu, 2016). Bu yöntemler arasında, flotasyon yöntemi 1920 'lerden beri toz boyutlu $(<0,5 \mathrm{~mm})$ kömürlerin temizlenmesinde başarı ile kullanılmaktadır (Canpolat, 2003; Gülsuna ve Bayat, 2010). Flotasyonda kömür ve gang minerallerinin yüzey hidrofobisite farklılığına bağlı olarak ayırma işlemi gerçekleştirilir (Tan ve diğ., 2015). Kömür taneleri beraber bulunduğu gang minerallerine göre daha fazla hidrofobik (su sevmez) özelliğe sahiptir. Hidrofobik kömür taneleri hava kabarcıklarına tutunarak yüzeye taşınıp temiz kömür olarak kazanılırken, gang mineralleri ise genellikle hidrofilik olduğundan hava kabarciklarına tutunamayı süspansiyonda kalırlar (Kawatra ve Eisele, 2001).

Kömür tanelerinin yüzebilirliği birçok faktör tarafından belirlenir (Xia ve diğ., 2017). Bu faktörler kömürleşme derecesi, nem içeriği ve yüzey oksidasyonudur (Bilir, 2011). Bununla birlikte kömür tanelerinin yüzebilirliğine etki eden diğer faktörler ise tane boyutu, pülpte katı oranı, hava miktarı, karıştırma hızı, besleme hızı, kullanılan reaktiflerin cinsleri ve miktarları, pülp $\mathrm{pH}^{\prime} 1$ ve flotasyon makinesidir (Sahinoglu, 2018).

Kömür flotasyonunda kömür tanelerinin yüzebilirliğini arttırmak ve daha kuvvetli kabarcık-tanecik bağları oluşturmak için genellikle gazyağı, mazot ve fuel oil gibi hidrokarbon kökenli polar olmayan yağlar toplayıcı olarak kullanılmaktadır. Bu yağlar kömür tanelerinin yüzeyini bir film şeklinde kaplamakta ve tane ile hava kabarcığı arasındaki adezyon kuvvetini arttırarak daha güçlü temasların oluşmasını sağlamaktadır. Böylelikle hem flotasyon hızı hem de kömür kazanma verimi artmaktadır (Hacifazlığlu, 2011). Bu tür yağlar polar olmayan hidrokarbon zincirinden oluştukları için kömür tanelerin yüzeylerini kaplarlar ve kömür tanelerinin doğal su sevmez özelliklerini arttırarak flotasyon başarısının arttırılmasına neden olurlar (Çilek, 2006). Taşkömürlerinin flotasyonunda yağların kulanım miktarları 0,5-2 kg/t civarında iken, linyit kömürlerinde bu miktar 6-8 kg/t seviyelerine kadar çıkabilmektedir. Diğer taraftan, polar olan (iyonlaşan) toplayıcılarda kömür flotasyonunda kullanılabilir. Fakat bu toplayıcılar polar olmayan yağlar kadar verimli olmayıp sadece kül giderimi açısından daha avantajlı olabilmektedirler (Hacıfazlığlu, 2011).

Literatürde kömür flotasyonunda farklı yağların performansının karşılaştırılması ile ilgili çeşitli çalışmalar olmasına rağmen, çalışmalarda kullanılan kömürlerin kükürt içerikleri (özellikle piritik kükürt içeriği) genellikle düşüktür. Diğer pek çok çalışmada atık ayçiçek yağının, petrol kökenli yağlara göre flotasyon performansı araştırılmamıştır. Bu çalışma kapsamında, kömür flotasyonunda yüksek yă̆ tüketimini ve düşük verim problemini çözmek için kolay bulunabilen, yenilenebilir yağın flotasyon reaktifi olarak kullanılabilirliği araştırılmıştır. Müzret bölgesinden alınan yüksek kül $(\% 35,65)$ ve kükürt $(\% 7,91)$ içerikli kömür farklı yağlar ile flotasyon işlemine tabi tutulmuş olup, elde edilen sonuçlar değerlendirilerek farklı yağların flotasyon performansları karşılaştırılmıştır. Çalışmada ileri karakterizasyon yöntemlerinden olan, taramalı elektron mikroskop (SEM) - enerji saçınım spektroskopisi (EDS), mikroskop altında parlak kesit incelemesi gibi yöntemler kullanılmıştır.

\section{MALZEME ve YÖNTEM (MATERIAL and METHOD)}

Bu çalışmada; Artvin ili, Yusufeli ilçesi, Müzret bölgesi kömürü kullanılmıştır. Bölgeden yaklaşık 150 kg kömür numunesi alınarak laboratuvara getirilmiştir. Laboratuvara getirilen kömür numunesinin miktarı konileme-dörtleme yöntemi ve mekanik numune bölücü kullanılarak azaltılmıştır. Elde edilen temsili örnekler laboratuvar tipi çeneli ve merdaneli kırıcı yardımıyla $-1,00 \mathrm{~mm}$ boyutuna indirilmiştir. Daha sonra çubuklu ve bilyalı değirmenler kullanılarak $-0,25 \mathrm{~mm}$ boyutunun altına öğütülmüştür. Kömür tane boyutu analizi Çizelge 1'de verilmiştir. Tane boyutu analizi ASTM E11 laboratuvar deney elekleri kullanılarak yapılmıştır. 
Çizelge 1. Kömür tane boyutu analizi Table 1. Analysis of coal particle size

\begin{tabular}{lll}
\multicolumn{3}{c}{ Table 1. Analysis of coal particle size } \\
\hline Tane Boyutu $(\mathrm{mm})$ & Ağırlı $(\%)$ & Kümülatif Elek Altı (\%) \\
\hline$-0,25+0,212$ & 12,79 & 100 \\
$-0,212+0,15$ & 18,31 & 87,21 \\
$-0,15+0,106$ & 14,38 & 68,90 \\
$-0,106+0,053$ & 21,88 & 54,52 \\
$-0,053$ & 32,64 & 32,64 \\
\hline Toplam & 100 & \\
\hline
\end{tabular}

Kömür numunesinin mineralojik ve kimyasal analizleri yapılmıştır. Minerolojik analizler, $\mathrm{X}$-ışını difraktometresi (XRD), taramalı elektron mikroskop (SEM) - enerji saçınım spektroskopisi (EDS), mikroskop altında parlak kesit incelemesi gibi yöntemler ve cihazlar kullanılarak belirlenmiştir. Kömür örneğinin XRD analizinde pirit, kaolinit, montmorillonit, illit, kalsit, jips ve kuvars tespit edilmiştir. Kömür örneğinin, SEM görüntüsü ve EDS analizleri Şekil 1'de, besleme numunesinde farklı noktalardan yapılan SEM-EDS analiz sonuçları Çizelge 2' de verilmiştir.
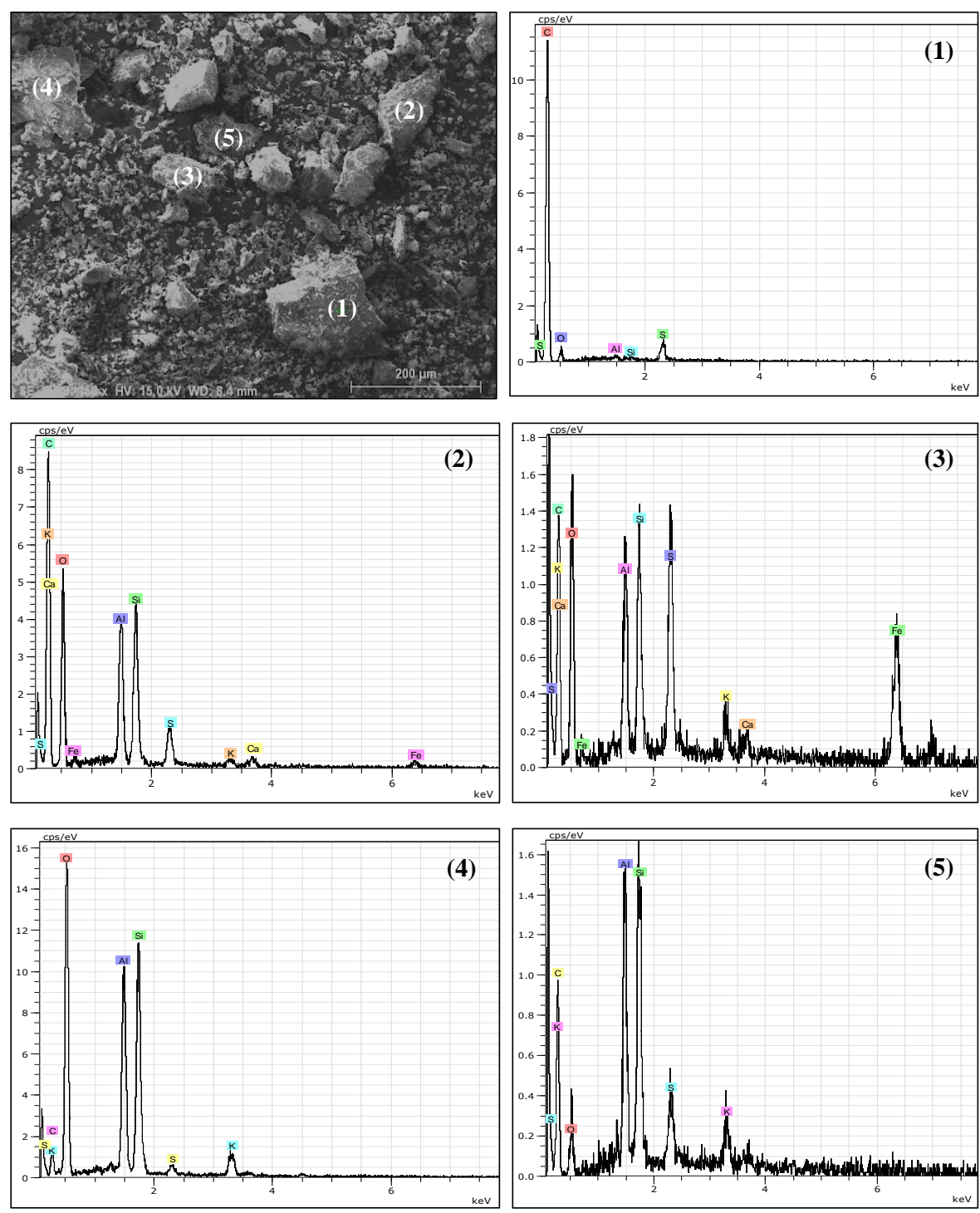

Şekil 1. Besleme numunesinin SEM görüntüsü ve EDS analizleri Figure 1. SEM image and EDS analysis of feed sample 
Çizelge 2. Besleme numunesinde farklı noktalardan yapılan SEM-EDS analiz sonuçları Table 2. SEM-EDS analysis results from different dots in feed sample

\begin{tabular}{cccccc}
\hline \multicolumn{6}{c}{ Besleme } \\
\hline Element (\%) & Nokta1 & Nokta2 & Nokta3 & Nokta4 & Nokta5 \\
\hline C & 75,56 & 30,46 & 15,66 & 2,84 & 38,32 \\
$\mathrm{O}$ & 21,37 & 45,07 & 28,25 & 59,49 & 43,77 \\
$\mathrm{Al}$ & 0,16 & 6,29 & 7,02 & 13,72 & 6,96 \\
$\mathrm{Si}$ & 0,31 & 9,46 & 8,29 & 18,48 & 7,08 \\
$\mathrm{~S}$ & 2,60 & 3,10 & 8,88 & 1,27 & 2,18 \\
$\mathrm{~K}$ & - & 1,24 & 2,84 & 4,20 & 1,69 \\
$\mathrm{Ca}$ & - & 1,25 & 1,35 & - & - \\
$\mathrm{Fe}$ & - & 3,13 & 27,71 & - & - \\
\hline
\end{tabular}

Bu analiz sonuçlarından, Şekil 1.'(1)'in kömür, (2)'nin kömür+kil+pirit, (3)' ün pirit+kil+kömür, (4)'ün kil, (5)'in çoğunluğu kömür olan kömür+kil olduğu belirlenmiştir. Çizelge 3'de Müzret kömürünün analiz sonuçları verilmiştir. Analiz sonuçlarından kömür numunesinin yüksek kül $(\% 35,65)$ ve kükürt $(\% 7,91)$ içeriğine sahip olduğu görülmüştür. Kömürün piritik kükürt içeriği ise \%5,57'dir. $-0,25 \mathrm{~mm}$ boyutuna indirilen kömür örneğinin parlak kesit incelemesinden de piritlerin farklı boyutta ve şekilde olduğu görülmüştür (Şekil 2).

Çizelge 3. Müzret kömürünün analiz sonuçları Table 3. Analysis results of Müzret coal

\begin{tabular}{lcc}
\multicolumn{3}{c}{ Table 3. Analysis results of Müzret coal } \\
\hline Bileşenler & Havada Kuru & Kuru \\
\hline Nem (\%) & 2,25 & - \\
Kül (\%) & 34,85 & 35,65 \\
Uçucu Madde (\%) & 10,73 & 10,98 \\
Sabit Karbon (\%) & 52,17 & 53,37 \\
Sülfat Kükürt (\%) & 0,99 & 1,01 \\
Piritik Kükürt (\%) & 5,44 & 5,57 \\
Organik Kükürt (\%) & 1,3 & 1,33 \\
Toplam Kükürt (\%) & 7,73 & 7,91 \\
Kalorifik Değer (kcal/kg) & 4970 & 5084 \\
\hline
\end{tabular}

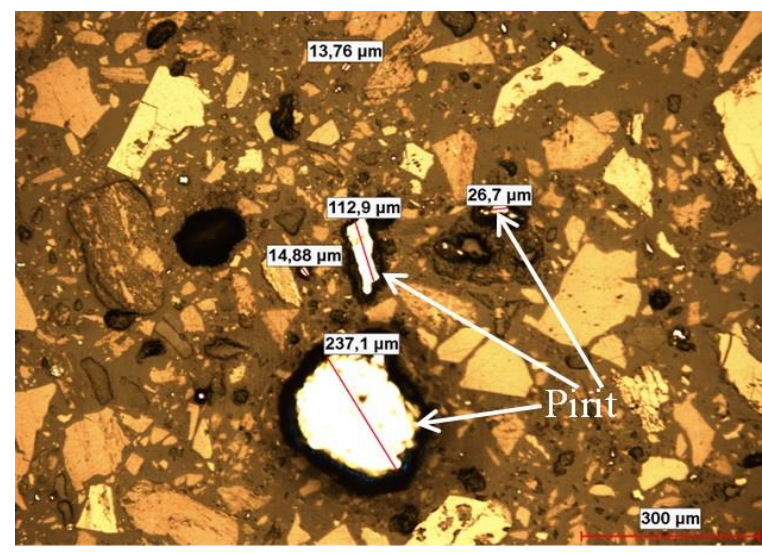

Şekil 2. Beslemedeki farklı şekil ve boyuttaki piritler Figure 2. Pyrites of different shapes and sizes in feed

$\mathrm{Bu}$ çalışmada, toplayıcı olarak mazot, fuel oil, orijinal ayçiçek yağı ve atık ayçiçek yağı kullanılmıştır. Çalışmada kullanılan yağların yoğunluk ve viskozite değerleri Çizelge $4^{\prime}$ de verilmiştir. Tüm yağların yoğunluk analizi $23,8^{\circ} \mathrm{C}^{\prime} \mathrm{de}$, viskozite analizi ise $40{ }^{\circ} \mathrm{C}^{\prime}$ de yapılmıştır. 
Çizelge 4. Yağların yoğunluk ve viskozite değerleri Table 4. Density and viscosity values of oils

\begin{tabular}{lll}
\multicolumn{3}{c}{ Table 4. Density and viscosity values of oils } \\
\hline Yağ Tipi & $\begin{array}{l}\text { Yoğunluk } \\
\left(\mathrm{g} / \mathrm{cm}^{3}\right)\end{array}$ & $\begin{array}{l}\text { Viskozite } \\
\left(\mathrm{mm}^{2} / \mathrm{s}\right)\end{array}$ \\
\hline Mazot & 0,832 & 2,76 \\
Fuel oil & 0,924 & 94,79 \\
Orijinal Ayçiçek Yağ1 & 0,918 & 32,24 \\
Atık Ayçiçek Yağ1 & 0,917 & 35,81 \\
\hline
\end{tabular}

Köpürtücü olarak ise çamyağı kullanılmıştır. Atık ayçiçek yağ edilmiştir. Atık yağ, içindeki fiziksel safsızlıkların giderilmesi amacıyla vakum filtre ile süzülmüştür. Yağların yoğunluğu Alla France tipi hidrometre ile, viskozitesi ise Tanaka AKV-202 tipi viskometre ile bulunmuştur.

Flotasyon deneyleri Denver tipi flotasyon makinesi kullanilarak 1 L'lik flotasyon hücresinde yapılmıştır. Tüm deneylerde kömür tane boyutu -0,25 mm olup, deneyler 1200 devir/dakika karıştırma hızında, \%10 katı oranında, 100 gr örnek kullanılarak gerçekleştirilmiştir. Bütün deneylerde ilk olarak kömür+su karışımı (900 ml su, 100 g kömür) 3 dakika karıştırılmış, daha sonra karışıma yağlar ilave edilip (250; 500; 750; $1000 \mathrm{~g} / \mathrm{t}) 5$ dakika şartlandırılmıştır ve ortama çamyağı ilavesi yapılıp (400 g/t) 2 dakika daha şartlandırılmıştır. Flotasyon makinasının havası açılarak (3 L/dk) 3 dakika köpük alınmıştır. Deneyler doğal pH'da saf su kullanılarak gerçekleştirilmiştir. Flotasyon deney koşuları Çizelge 5’de verilmiştir. Flotasyon prosesinde kullanılan karıştırma hızı, şartlandırma süreleri ve kullanılan dozaj değerleri, ön optimizasyon çalışmasıyla belirlenmiştir. Elde edilen konsantreler vakum filtre ile susuzlandırılıp, daha sonra etüvde $105^{\circ} \mathrm{C}^{\prime}$ de kurutulup tartılmış ve kül analizine tabi tutulmuştur.

Çizelge 5. Flotasyon deney koşulları Table 5. Flotation test conditions

\begin{tabular}{ll}
\multicolumn{2}{c}{ Table 5. Flotation test conditions } \\
\hline Parametre & Değer \\
\hline Selül Hacmi & $1 \mathrm{~L}$ \\
Katı Oranı & $\% 10$ \\
Karıştırma Hızı & $1200 \mathrm{dev} / \mathrm{dk}$ \\
Toplayıcı & $250 ; 500 ; 750 ; 1000 \mathrm{~g} / \mathrm{t}$ \\
Köpürtücü & $400 \mathrm{~g} / \mathrm{t}$ \\
Hava Miktarı & $3 \mathrm{~L} / \mathrm{dk}$ \\
Köpük Toplama Zamanı & $3 \mathrm{dk}$ \\
\hline
\end{tabular}

Aşağıdaki eşitlikler kullanılarak, yanabilir verim (YV, \%), kül giderimi (KG, \%) ve ayırma etkinliği (AE, \%) hesaplanmıştır (Sahinoglu, 2018).

$$
\begin{aligned}
& \mathrm{YV}(\%)=\left[\frac{\mathrm{C}(100-\mathrm{c})}{\mathrm{F}(100-\mathrm{f})}\right] \times 100 \\
& \mathrm{KG}(\%)=\left[1-\frac{\mathrm{C}}{\mathrm{F}} \frac{\mathrm{c}}{\mathrm{f}}\right] \times 100 \\
& \mathrm{AE}(\%)=[\mathrm{YV}(\%)+\mathrm{KG}(\%)-100]
\end{aligned}
$$

Burada;

C, Konsantrenin ağırlığı (g); c, Konsantrenin külü (\%); F, Beslemenin ağırlığ (g); f, Beslemenin külü (\%). 


\section{BULGULAR ve TARTIŞMA (RESULTS and DISCUSSIONS)}

Farklı yağların (mazot, fuel oil, orijinal ayçiçek yağı ve atık ayçiçek yağı) ve yağ miktarlarının (250, 500, 750, $1000 \mathrm{~g} / \mathrm{t}$ ) değişken olarak kullanıldığ flotasyon deneylerinde elde edilen yanabilir verim, kül giderimi ve ayırma etkinliği sonuçları Şekil 3'de gösterilmiştir.

Mazot ile yapılan deneylerde yanabilir verim \%82,7-87,48 arasında, kül giderimi \%33,86-52,08 ve ayırma etkinliği \%21,34-34,78 arasında değişmektedir. Fuel oil ile yapılan deneylerde yanabilir verim $\% 77,58-82,23$ iken, kül giderimi $\% 53,69-58,36$ ve ayırma etkinliği \%35,92-36,58' dır. Orijinal ayçiçek yağ1 ile yapılan deneylerde yanabilir verim \%80,69-85,9 olup, kül giderimi \%35,81-56,2 ve ayırma etkinliği $\% 21,71-36,89$ arasında değişmektedir. Atık ayçiçek yağı ile yapılan deneylerde ise yanabilir verim \%79,43-84,19 iken, kül giderimi \%38,5-56,17 ve ayırma etkinliği \%22,69-35,6' dır.
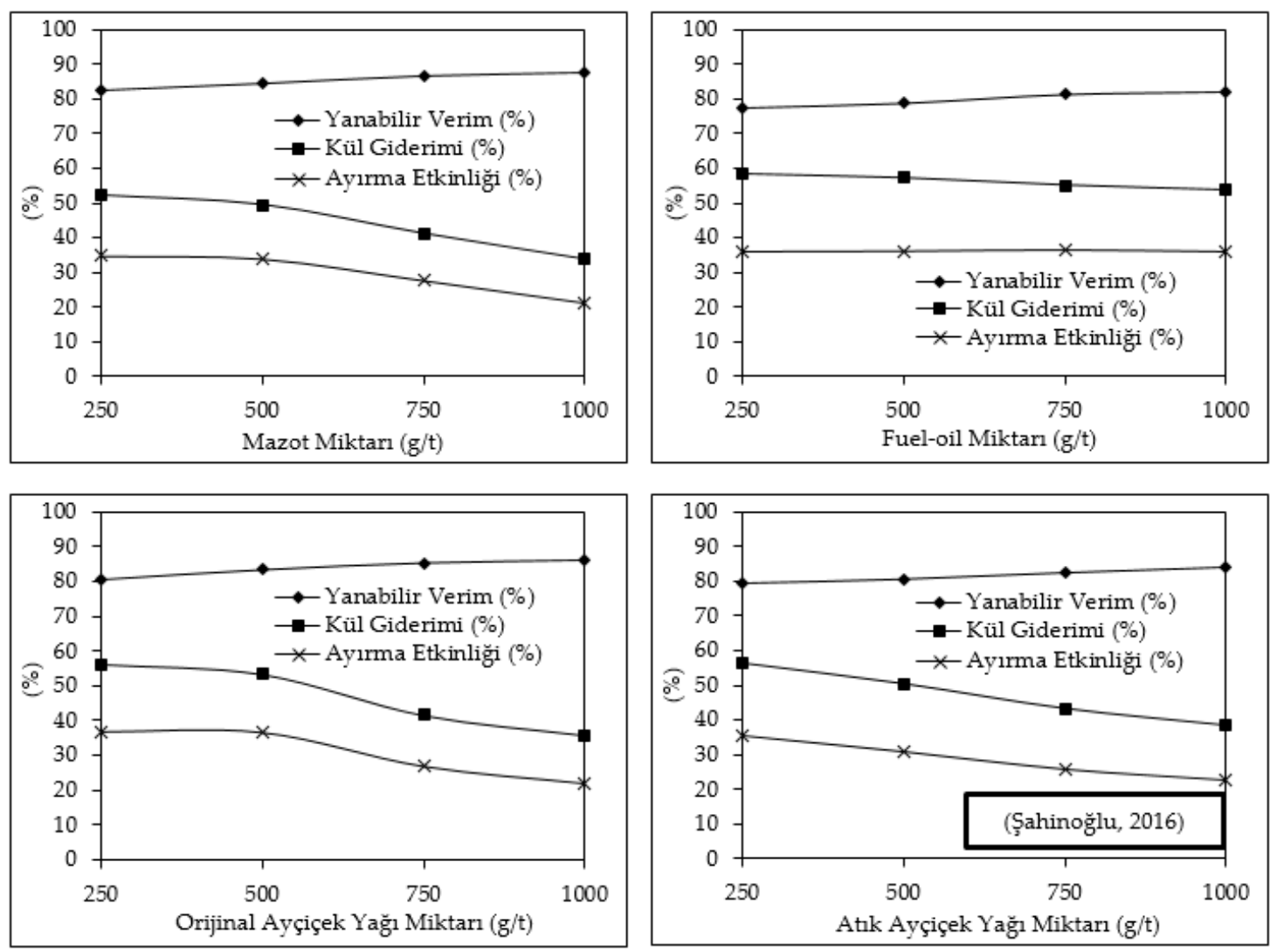

Şekil 3. Yağ tipinin ve miktarının yanabilir verim, kül giderimi ve ayırma etkinliğine etkisi Figure 3. The effect of oil type and amount on combustible recovery, ash rejection and separation efficiency

Tüm yağlar için yağ miktarlarının artışına bağlı olarak yanabilir verimlerin arttı̆̆ı, kül giderimlerinin ise azaldığı görülmüştür. Pülp ortamında daha fazla yağ damlası bulunmasıyla birlikte kömür taneleriyle daha fazla temasın olması kömür tanelerinin hidrofobluğunun artmasına neden olmaktadır. Kömür taneciklerinin hidrofobluğunun artması, tane ile hava kabarcıkları arasındaki tutunmanın daha kuvvetli olmasını sağlamaktadır. Bu durum yanabilir verimlerin artmasını neden olmuştur. Yağ miktarlarının artışına bağlı olarak kül giderimlerinin azalması, ortamdaki yă̆ damlacıklarının sayısının daha da artması yüksek mineral madde içerikli kömür tanecikleri üzerine daha fazla yağ adsorbe olması sonucu yüzdürülen mineral madde miktarının artmasıyla açıklanabilir. Besleme numunesinin yapılan SEM-EDS analiz sonuçlarından (Şekil 1, Çizelge 2) gang minerallerinin kömür taneleriyle birlikte buluna bildiği (kömür+kil+pirit, kömür+kil) belirlenmiş olup, yă̆ miktarlarının artışına bağlı olarak kömür taneleriyle birlikte bulanan gang minerallerininde konsantreye geldiği söylenebilir. Genel olarak bütün yă̆ tiplerinde yağ miktarlarının artışıyla birlikte ayırma 
etkinlikleri azalmıştır. Ayırma etkinliği hem yanabilir verimi hem de kül giderimini birlikte değerlendiren bir kriterdir. Bu değer ne kadar yüksek ise temizleme (zenginleştirme) işlemi o kadar başarılıdır. Yağ miktarlarının artışıyla birlikte yanabilir verimlerinin artmasına rağmen, kül giderimlerinin azalması ve de bu azalmaların yanabilir verimdeki artışa oranla daha fazla olması bu sonucu ortaya çıkarmıştır.

Sönmez ve Cebeci (2006) çalışmalarında -500 mluk Ukrayna kömürünün flotasyon yöntemi ile temizlenebilirliğini farklı toplayıcılar kullanarak araştırmışlar. Toplayıcı miktarlarının artışına bağlı olarak yanabilir verimlerin arttığını, kül giderimlerinin ise azaldığını rapor etmişlerdir. Ayırma etkinliği değerlerinin toplayıcı miktarlarının artışına bağlı olarak arttığını ancak bazı toplayıcılarda belli yağ miktarlarından sonra ayırma etkinliği değerlerinin azaldığını belirlemişlerdir. Şimşek (2007) çalışmasında farklı kömürlerin flotasyon ile zenginleştirilmesinde toplayıcı olarak gazyağı, fuel oil, pamukyağı, susamyağı, zeytinyağı ve soya yağı kullanmıştır. Yağ miktarı arttıkça yanabilir verimin arttığını, genel olarak kül giderimi değerlerinin ise azaldığını belirlemiştir.

Şekil 4'de görüldüğü gibi bütün yağ miktarları için en yüksek yanabilir verim değerleri sırasıyla mazot, orijinal ayçiçek yağı, atık ayçiçek yağı ve fuel oil ile elde edilmiştir. Tüm deneyler içerisinde maksimum yanabilir verime $1000 \mathrm{~g} / \mathrm{t}$ yağ miktarında \%87,48 olarak mazot ile ulaşılmıştır. En düşük yanabilir verim değerine ise $250 \mathrm{~g} / \mathrm{t}$ yağ miktarında \%77,58 olarak fuel oil kullanıldığında ulaşılmıştır. Mazot kullanıldığında yanabilir verimin maksimum olması mazotun yoğunluğunun ve viskozitesinin diğer yağlara göre daha az olması nedeniyle pülp içerisinde daha iyi dağılarak homojen bir emülsiyon oluşturmasına dayandırılabilir. 5 dakikalık şartlandırma süresi sonunda mazotun kömür taneleri yüzeylerine diğer yağlara göre daha fazla adsorplandığı söylenebilir. Bu durumun yanabilir verimin daha fazla olmasını sağladığı düşünülmüştür. Fuel oil ile diğer yağlara göre daha düşük yanabilir verim değeri elde edilmesinin nedeni ise yoğunluğunun ve viskozitesinin daha yüksek olmasıdır. 5 dakikalık şartlandırma süresi sonunda yüksek yoğunluğu ve viskozitesi sebebiyle pülp içerisinde yeterince homojen olarak dağılamayan fuel oil, kömür taneleri yüzeylerine yeterince adsorplanamadığı söylenebilir. Bundan dolayı daha düşük yanabilir verim değerleri elde edilmiştir. Kül giderimleri bütün yağ miktarları için en fazla fuel oil kullanıldığında, en az ise mazot kullanıldığında elde edilmiştir. Maksimum kül giderimine $250 \mathrm{~g} / \mathrm{t}$ yağ miktarında \%58,36 olarak fuel oil kullanıldığında, minumum kül giderimine ise $1000 \mathrm{~g} / \mathrm{t}$ yağ miktarında \%33,86 olarak mazot kullanıldığında ulaşılmıştır. Ayırma etkinliği genel olarak düşük yağ miktarlarında (250; $500 \mathrm{~g} / \mathrm{t}$ ) bütün yağlar için birbirine yakın olmakla birlikte yüksek yağ miktarlarında fuel oil kullanıldığında daha fazla olmuştur. Bu durum, ayırma etkinliğinin hem yanabilir verimi hem de kül giderimini birlikte değerlendiren bir kıstas olmasından kaynaklanmaktadır. Şöyle ki, yüksek yağ miktarlarında (500; $1000 \mathrm{~g} / \mathrm{t}$ ) fuel oil kullanıldığında elde edilen yanabilir verim değerleri diğer yağlarla elde edilen yanabilir verim değerlerine göre daha az olsa da, kül giderim değerlerinin diğer yağlara göre çok daha fazla olması bu sonucu ortaya çıkarmıştır. Maksimum ayırma etkinliği $250 \mathrm{~g} / \mathrm{t}$ yağ miktarında \%36,89 olarak orijinal ayçiçek yağı kullanıldığında elde edilmiştir.

Atık ayçiçek yağı ile yapılan flotasyon deneylerinde her ne kadar maksimum değerler elde edilmemiş olsa da elde edilen sonuçlar incelendiğinde hemen hemen diğer yağlarla elde edilen sonuçlara yakın değerler olduğu görülmüştür. Atık ayçiçek yağının yoğunluğunun ve viskozitesinin orijinal ayçiçek yağının yoğunluğu ve viskozitesine göre yakın değerde olduğu görülmüştür. Atık ayçiçek yağ 1 ile $250 \mathrm{~g} / \mathrm{t}$ yağ miktarında yanabilir verim \%79,43 iken, kül giderimi \%56,17 olarak bulunmuştur. Bu yağ miktarında ayırma etkinliği ise \%35,6'dir. Bu sonuçlardan da görüleceği gibi atık ayçiçek yağının flotasyona ilişkin özelliklerinde önemli bir değişme olmadığ1 belirlenmiştir. Hacıfazlıoğlu ve Gerdan (2016) yaptıkları çalışmada toz boyutlu kömürün flotasyonunda toplayıcı olarak atık ayçiçek yağını kullanmışlar. \%55,85 küllü Zonguldak toz kömüründen yanabilir verimi $\% 28,19$ ve ürün külünü ise \%15,80 olarak bulmuşlardır. Şimşek (2007) çalışmasında dört farklı bitkisel yağın (pamukyağı, susamyağı, zeytinyağı ve soya yağı) $175^{\circ} \mathrm{C}$ kızartılmasıyla elde ettiği atık yağları, taşkömürü ve linyit kömürlerinin flotasyonunda etkisini incelemiş, bu yağların da oldukça etkili olduğunu ve sonuçların orijinal yağlara göre hemen hemen aynı olduğunu bulmuştur. 

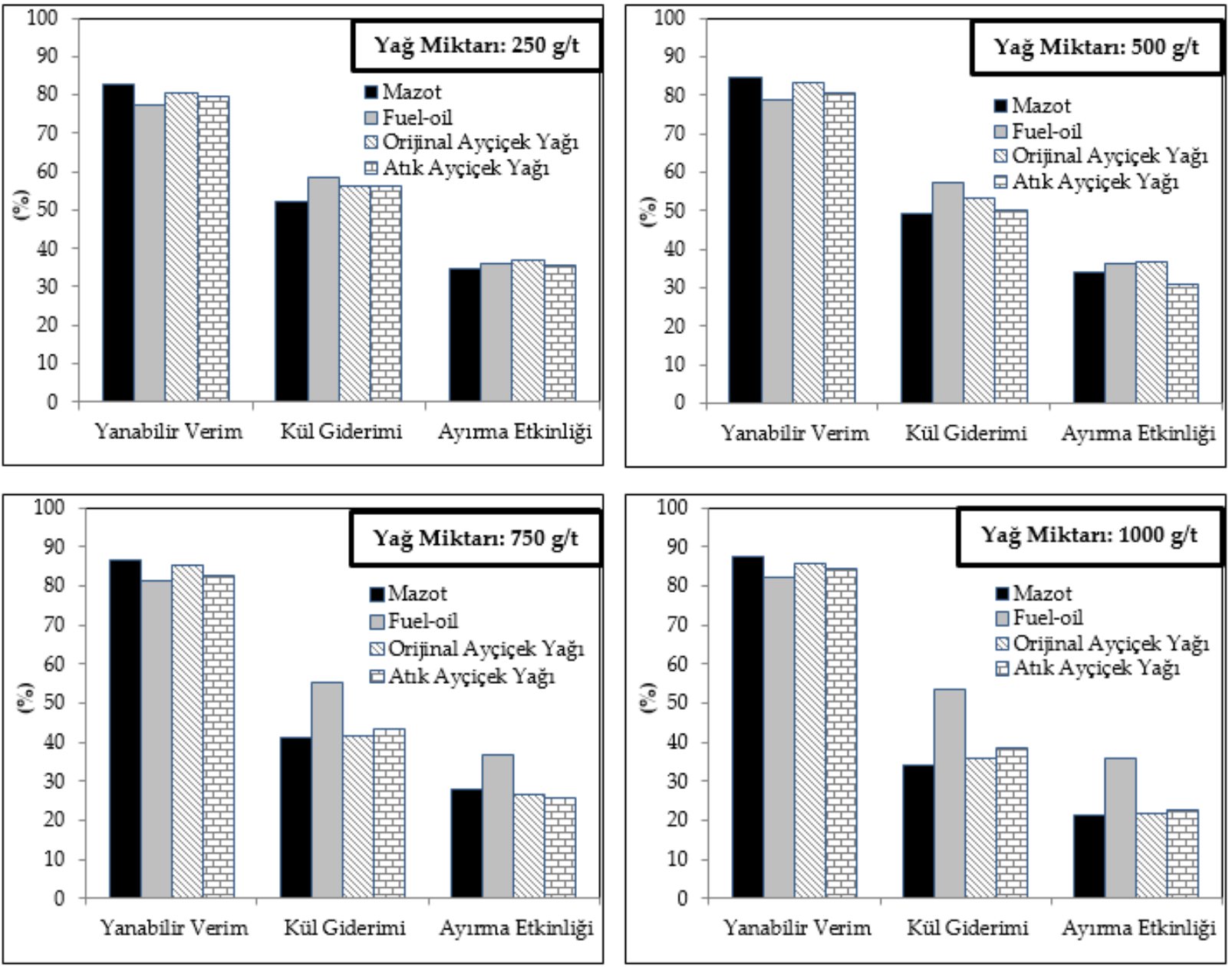

Şekil 4. Farklı yağların, çeşitli yağ miktarlarındaki performanslarının karşılaştırılması Figure 4. Comparison of performance of various oils in different oil quantities

Şekil 5'de beslemenin, orijinal ayçiçek yağı ile $250 \mathrm{~g} / \mathrm{t}$ yağ miktarında yapılan flotasyon deneyinin konsantresinin ve atığının parlak kesitte görünümleri karşılaştırmalı olarak verilmiştir. Parlak kesitler incelendiğinde piritlerin daha çok atığa gittiği belirlenmiştir. Atıktaki piritlerin çoğunlukla iri boyutlu olduğu, bununla birlikte de küçük boyutlu piritlerinde bulunduğu gözlemlenmiştir. Konsantredeki piritlerin ise genellikle küçük boyutlu piritler olduğu görülmüştür. Konsantrenin parlak kesitinde çok fazla miktarda iri, orta ve küçük boyutlu maserallerin olduğu, bununla birlikte az da olsa genellikle orta ve küçük boyutlu maserallerinde attğa gittiği belirlenmiştir.

Ayırma etkinliği en fazla olan orijinal ayçiçek yağı ile $250 \mathrm{~g} / \mathrm{t}$ yağ miktarında yapılan flotasyon deneyinde elde edilen temiz kömürün analiz sonuçları Çizelge 6 ' da verilmiştir.

Çizelge 3 ve Çizelge 6 karşılaştırıldığında kül içeriğinin \%35,65 ‘den \%23,12’ye düştüğü, piritik kükürt içeriğinin \%5,57'den \%1,93'e azaldığı, kalorifik değerin ise $5084 \mathrm{kcal} / \mathrm{kg}^{\prime}$ dan $5863 \mathrm{kcal} / \mathrm{kg}^{\prime} \mathrm{a}$ yükseldiği görülmüştür.

Çizelge 6. Temiz kömürün analiz sonuçları Table 6. Analysis results of clean coal

\begin{tabular}{ll}
\hline Bileşenler & Kuru \\
\hline Kül (\%) & 23,12 \\
Piritik Kükürt (\%) & 1,93 \\
Kalorifik Değer (kcal/kg) & 5863 \\
\hline
\end{tabular}



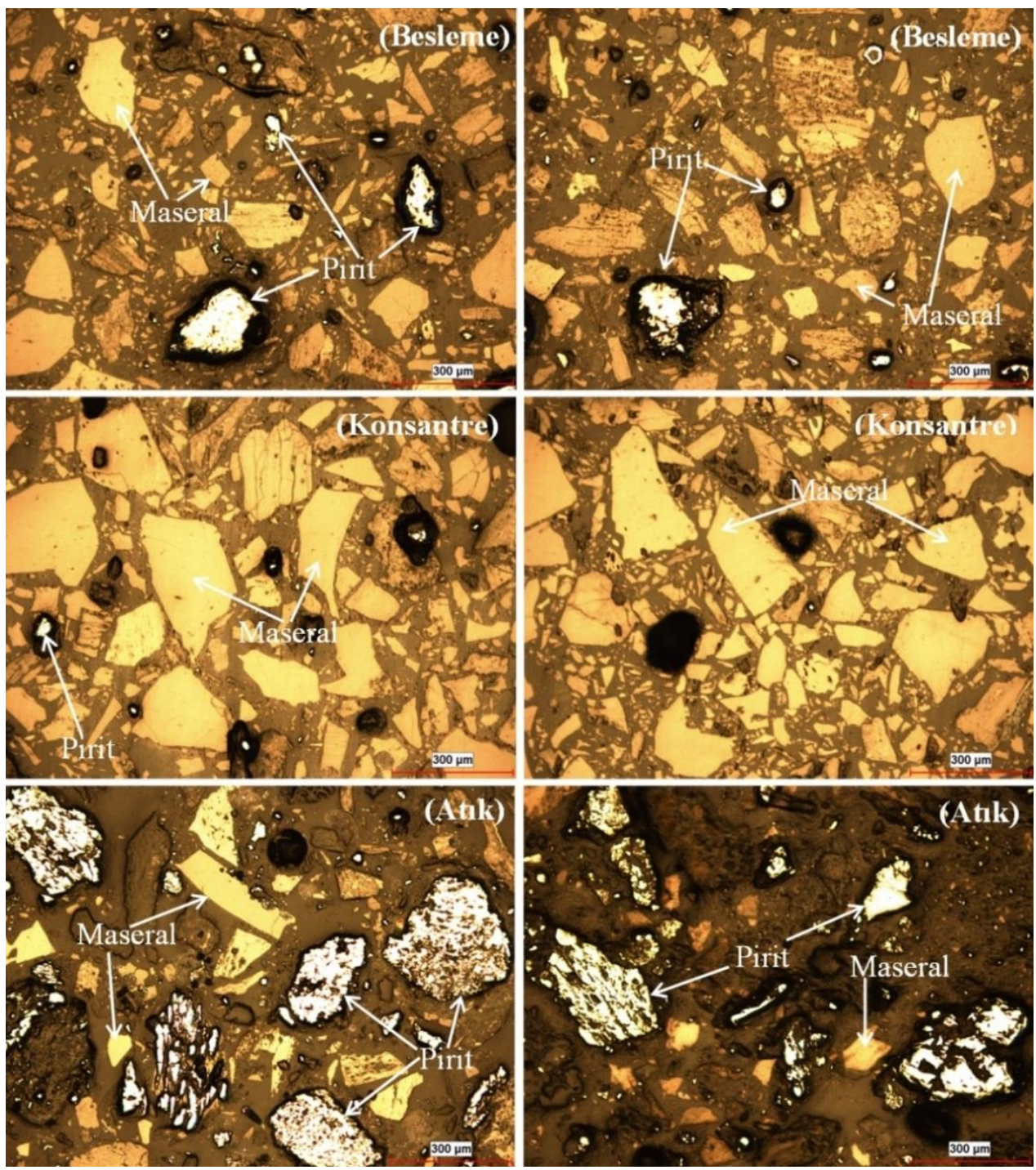

Şekil 5. Besleme, konsantre ve atığın parlak kesit görüntüleri

Figure 5. Polished section images of feed, concentrate and tailings

\section{SONUÇLAR (CONCLUSIONS)}

Farklı yağların yüksek kül-kükürt içerikli Müzret kömürünün flotasyonunda başarılı bir şekilde kullanılabildiği, yüksek oranlarda yanabilir verim ve kül giderimleri elde edildiği görülmüştür.

Tüm deneyler arasında maksimum yanabilir verim \%87,48 olarak mazot ile $1000 \mathrm{~g} / \mathrm{t}$ yağ miktarında, en yüksek kül giderimi $250 \mathrm{~g} / \mathrm{t}$ yağ miktarında \%58,36 olarak fuel oil ile, en fazla ayırma etkinliği ise 250 $\mathrm{g} / \mathrm{t}$ yağ miktarında orijinal ayçiçek yağı kullanıldığında \%36,89 olarak bulunmuştur.

Besleme numunesi (kuru bazda) analiz sonuçları, ayırma etkinliği en fazla olan deneyde elde edilen sonuçlarla karşılaştırıldığında kül ve piritik kükürt içeriklerinin sırasıyla $\% 35,15$ ve $\% 65,35$ oranlarında azaldığı, kalorifik değerin ise \%15,32 oranında arttığı bulunmuştur.

Kömür flotasyonunda mazot ve fuel oil gibi petrol kökenli yağlara alternatif olarak bitkisel kökenli yağlarında başarılı bir şekilde kullanılabileceği görülmüştür.

Atık ayçiçek yağının flotasyon performansının diğer yağların flotasyon performansına yakın olduğu belirlenmiştir. 


\section{KAYNAKLAR (REFERENCES)}

Alp, İ., Şahinoğlu, E., Kantarcı, S., 2017, “Tersiyer (Pliyosen)Yaşlı Bir Kömür Arama Sahasına Ait Sondaj Karot Örneklerinin Değerlendirilmesi", Engineering Sciences, Vol. 12 (4), pp. 224-235.

Bilir, K., 2011, “Kömür Flotasyonunda Kullanılan Gazyağı Miktarının Oranların Farkı Testi ile Optimizasyonu", Eskişehir Osmangazi Mühendislik Mimarlık Fakültesi Dergisi, 24, 119-130.

Canpolat, L., 2003, "Taşkömürünün Yă̆ Aglomerasyonu, Flotasyon ve Yă̆ Aglomerasyonu-Flotasyon Yöntemiyle Zenginleştirilebilirliğinin İncelenmesi", Yüksek Lisans Tezi, Cumhuriyet Üniversitesi, Fen Bilimleri Enstitüsü, Sivas.

Çilek, E.C., 2006, Mineral Flotasyonu, Süleyman Demirel Üniversitesi Mühendislik-Mimarlık Fakültesi, Yayin No: 59, Isparta.

Gülsuna, G., Bayat, O., 2010, “Linyit Kömürü Ara Ürününün Flotasyon ile Zenginleştirilmesinin Araştırılması", Ç.Ü. Fen Bilimleri Enstitüsü, Cilt 22-3, ss. 170-176.

Hacıfazlıŏlu, H., 2011, “Jameson Hücresinde Bitümlü Şlam Kömürün Flotasyonu İçin En Uygun Köpürtücü ve Toplayıc1 Tipinin Araştırılması", Dicle Üniversitesi Mühendislik Fakültesi Mühendislik Dergisi, Cilt 2, ss. 33-43.

Hacıfazlıŏ̆lu, H., Gerdan, G.H., 2016, "Taşkömürü Tozları Flotasyonunda Sıcaklığın Etkisi”, Adıyaman Üniversitesi Mühendislik Bilimleri Dergisi, Cilt 5, ss. 1-8.

Kawatra, S.K., Eisele, T.C., 2001, Coal Desulfurization High-Efficiency Preparation Methods, Department of Mining and Materials Processing Engineering Michigan Technological University.

Sahinoglu, E., 2018, "Cleaning of High Pyritic Sulfur Fine Coal via Flotation", Advanced Powder Technology, Vol. 29, pp. 1703-1712.

Sönmez, İ., Cebeci, Y., 2006, "Performance of Classic Oils and Lubricating Oils in Froth Flotation of Ukraine Coal", Fuel, Vol. 85, pp. 1866-1870.

Şahinoğlu, E., 2012, "Kömürün Yağ Aglomerasyonu Yöntemi ile Temizlenmesinde Bitkisel Atık Yağların ve Ses Ötesi Dalgaların Kullanılabilirliğĭ", Doktora Tezi, Karadeniz Teknik Üniversitesi, Fen Bilimleri Enstitüsü, Trabzon.

Şahinoğlu, E., 2016, "Kömürün Flotasyon ile Temizlenmesinde Atık Ayçiçek Yağının Kullanılabilirliği", International Multidisciplinary Congress of Eurasia, Ukraine, Odessa, 32-39, 11-13 July 2016.

Şimşek, S., 2007, "Farkh Kömürlerin Flotasyon ile Zenginleştirilmesinde Klasik Flotasyon Yağları ile Bitkisel Kökenli Yağların Performanslarının Karşılaştırılması", Doktora Tezi, Cumhuriyet Üniversitesi, Fen Bilimleri Enstitüsü, Sivas.

Tan, J., Liang, L., Peng, Y., Xie, G., 2015, “Grinding Flotation of Bituminous of Different Oxidation Degrees", International Journal of Mineral Processing, Vol. 142, pp. 30-34.

Xia, W., Li, Y., Nguyen, A.V., 2018, "Improving Coal Flotation Using the Mixture of Candle Soot and Hydrocarbon Oil As a Novel Flotation Collector", Journel of Cleaner Production, Vol. 195, pp. 1183-1189.

Xia, W., Niu, C., Zhang, Z., 2017, “Effects of Attrition on Coarse Coal Flotation in the Absence of Collectors", Powder Technology, Vol. 310, pp. 295-299. 